\title{
Seropositivity to anti-phenolic glycolipid-I in leprosy cases, contacts and no known contacts of leprosy in an endemic and a non-endemic area in northeast Brazil
}

\author{
Cristiane C. Frota ${ }^{\mathrm{a}, *}$, Max V.C. Freitas ${ }^{\mathrm{a}}$, Norma T. Foss ${ }^{\mathrm{b}}$, Luana N.C. Lima ${ }^{\mathrm{a}}$, \\ Laura C. Rodrigues ${ }^{c}$, Maurício L. Barreto ${ }^{\mathrm{d}}$, Ligia R.S. Kerr ${ }^{\mathrm{e}}$ \\ a Departamento de Patologia, Faculdade de Medicina, Federal University of Ceará, Fortaleza, CE, Brazil \\ b Departamento de Clínica Médica, Faculdade de Medicina, University of São Paulo, São Paulo, SP, Brazil \\ ${ }^{c}$ London School of Hygiene and Tropical Medicine, Keppel Street, London, UK \\ d Instituto de Saúde Coletiva, Federal University of Bahia, Salvador, BA, Brazil \\ e Departamento de Saúde Comunitária, Faculdade de Medicina, Federal University of Ceará, Fortaleza, CE, Brazil
}

\section{A R T I C L E I N F O}

\section{Article history:}

Received 20 April 2009

Received in revised form 15 March 2010

Accepted 15 March 2010

Available online 6 May 2010

\section{Keywords:}

Leprosy

Mycobacterium leprae

Seroprevalence

Immunologic marker

Phenolic glycolipid-I

Brazil

\begin{abstract}
A B S T R A C T
The seroprevalence rates of IgM anti-phenolic glycolipid-I (PGL-I) antibodies in four study groups with differing exposure to Mycobacterium leprae in Ceará, Brazil were investigated between March 2005 and August 2006. The first three groups in a high prevalence area included 144 cases of leprosy, their 380 contacts and 317 participants with no known leprosy contact. The fourth group in a low prevalence area consisted of 87 participants with no known leprosy contact living in an area in which no cases of leprosy had been reported in the previous 6 months. Seropositivity and levels of IgM antibodies to PGL-I were investigated using ELISA. The seropositivity levels of anti-PGL-I among the different clinical forms of leprosy cases were $61 \%$ for lepromatous, $25 \%$ for tuberculoid and $27 \%$ indeterminate. The levels of anti-PGL-I antibodies in the endemic area differentiated leprosy cases from noncases. However, the seropositivity was similar among contact cases (15.8\%) and no known leprosy contact cases from high (15.1\%) and low (13.8\%) prevalence areas. The seropositivity of both contacts and no known contacts was much higher than previously reported among no known contacts in other endemic areas. The study indicates that anti-PGL-I antibodies are not useful as immunological markers of household leprosy contacts and no known leprosy contacts in endemic areas.
\end{abstract}

(c) 2010 Royal Society of Tropical Medicine and Hygiene. Published by Elsevier Ltd. All rights reserved.

\section{Introduction}

Leprosy is a chronic infectious disease with a long incubation period. The diagnosis is not straightforward and depends on clinical symptoms, microscopy and/or biopsy. Although the rate of disease is higher among those who

\footnotetext{
* Corresponding author. Present address: Departamento de Patologia e Medicina Legal, Faculdade de Medicina, Universidade Federal do Ceará, Rua Monsenhor Furtado s/n, 60441-750 Fortaleza, CE, Brazil.

E-mail address: ccfrota@hotmail.com (C.C. Frota).
}

have contact with a person with leprosy, early detection is difficult in the absence of a test. Serologic tests have been studied for leprosy diagnosis, but most of them are not useful for this purpose. An ELISA to detect IgM antibodies against phenolic glycolipid-I (PGL-I) has been extensively studied as a tool for leprosy diagnosis, especially among contacts. ${ }^{1,2}$ The IgM antibodies are considered to be specific to Mycobacterium leprae. ${ }^{3,4}$ Anti-PGL-I seropositivity of about $3 \%$ has been reported in the general population in Indonesia and South India, 5,6 and of 3.2\% among those in occupational contact with leprosy cases in Spain. ${ }^{7}$ Seropositivity in household contacts has been reported as $8.3 \%$ 
in Spain and $13 \%$ in a post-elimination leprosy region of Colombia. 8

Most studies of the incidence of leprosy in people seropositive to anti-PGL-I have failed to show an increased risk. However, increases in the rate of leprosy in seropositive contacts compared with seronegative contacts have been found in Indonesia ${ }^{5}$ and Brazil. ${ }^{9}$ Bakker has also described higher positivity in cases, with the highest seropositivity in multibacillary (MB) cases (60\%) and intermediate seropositivity in borderline lepromatous cases (35.1\%), while most paucibacillary (PB) patients were seronegative. $^{5}$

Most studies of anti-PGL-I antibodies have been conducted in areas of high leprosy prevalence. Brazil reported 284626 new cases of leprosy between 2001 and 2006. ${ }^{10}$ About $8.4 \%$ of these cases were diagnosed among those younger than 15 years of age. Brazil still has recent transmission and active disease throughout the country. ${ }^{11}$

Northeast Brazil is considered a very highly endemic area for leprosy. Ceará State had a detection rate of 2.9/10000 inhabitants in 2006. ${ }^{12}$ A recent geographical analysis conducted in this state showed that the distribution of leprosy is heterogeneous, ${ }^{13}$ similar to that found worldwide. ${ }^{14}$ The reason behind this is not clear, but social inequalities and uncontrolled urbanization appear to play important roles in this distribution. ${ }^{15}$ There are many municipalities in this area where there is a prevalence of less than 0.1 per 10000 inhabitants and a few where the prevalence is as high as 14.8 per 10000 people. The aim of this study was to compare the prevalence rates of IgM antiPGL-I antibodies in two distinct municipalities of Ceará State, Brazil, one with a high and the other with a low detection rate of leprosy.

\section{Materials and methods}

\subsection{Study area}

This was a cross-sectional study conducted in two municipalities of Ceará State in northeastern Brazil: Mulungu and Sobral. These sites were selected because of their differences: size of urban population (9798 and 178916 inhabitants in Mulungu and Sobral, respectively), geographical location (the central interior of Ceará and northwest of Ceará, respectively), environment (mountain forests with mild weather and sea-level with high temperatures, respectively), population covered by the Family Health Program (FHP) (65\% in Mulungu and 95\% in Sobral), and detection rate of leprosy (1.0 and 9.3 cases/10 000 inhabitants in 2006 in Mulungu and Sobral, respectively). Sobral is a city that has grown demographically and economically, while these factors have remained static in Mulungu. The state of Ceará has over 8 million inhabitants, and about half of the population is classified as living below the poverty line. ${ }^{16}$ The study was conducted from March 2005 to August 2006.

\subsection{Population}

In Mulungu, which is considered historically as a low prevalence area, there is only one health unit that offers laboratory tests. Consequently, this unit provides much of the health care in the municipality, and 87 patients aged 15 years and over participated in the study. None of these patients presented any signs or symptoms of leprosy, and nor did they report any contact with leprosy cases.

In Sobral, the high prevalence area, the case-control study adopted the following procedure. All suspected cases of leprosy were referred by physicians of the FHP to a trained professional, who then confirmed the presence of the disease after clinical skin examination, skin smear and biopsy. Cases were classified using Ridley-Jopling criteria ${ }^{17}$ based on histological study, and bacterial indexes (BI) were assessed. Controls were selected in two different ways. Those who had lived for at least 5 years in the household of a leprosy case and were aged 15 years or older were termed contacts. We had also collected data from controls, termed no known leprosy contacts, selected randomly from neighbours in proportion to the demographic density within the urban area. In each household, one person aged 15 years or over was selected as a control. A total of 144 leprosy cases, 380 contacts and 317 no known leprosy contacts were selected.

\subsection{Field and laboratory procedures}

A questionnaire was completed for all leprosy cases, contacts and no known contact controls to collect demographic, socioeconomic, environmental and behavioural data. The cases were classified using both the RidleyJopling ${ }^{17}$ and WHO-operational classifications. ${ }^{18}$ Blood samples were collected from all participants by peripheral venipuncture. After centrifugation, the serum was frozen at $-20^{\circ} \mathrm{C}$ until used.

Detection of IgM antibodies to PGL-I was performed using an ELISA as previously described. ${ }^{19}$ Disaccharide bovine serum albumin (DBSA) was used as a semi-synthetic analogue of PGL-I. Ninety-six-well polystyrene plates were coated with DBSA in sodium carbonate buffer $(2 \mu \mathrm{g} / \mathrm{ml})$, $\mathrm{pH} 9.6$ and stored at $4{ }^{\circ} \mathrm{C}$ until used. The serum from each patient was diluted 1:100 in $15 \mathrm{mM}$ Tris-Tween buffer containing $5 \%$ sheep serum, and $10 \mu \mathrm{l}$ was distributed per well and incubated in a humid chamber at $37^{\circ} \mathrm{C}$ for $\mathrm{l}$ h. At the end of this period, the samples were washed with $15 \mathrm{mM}$ TrisTween buffer, and then anti-human IgM beta-galactosidase conjugate diluted 1:600 in 15 mM Tris-Tween buffer containing $5 \%$ sheep serum was added. The plates were then incubated at $37^{\circ} \mathrm{C}$ for $1 \mathrm{~h}$. A fluorogenic substrate $(10 \mu 14$ methylumbelliferyl beta-D-galactopyranoside) was added to the samples, and the material was incubated at $37^{\circ} \mathrm{C}$ for $30 \mathrm{~min}$. The plate was read with a multiscan ELISA reader. Sera with an absorbance at $450 \mathrm{~nm}$ greater than 0.028 (the mean absorbance plus three standard deviations of 35 healthy Brazilian control subjects from São Paulo State) were considered positive. Each serum sample was tested in duplicate, and results classified as mean absorbance of the duplicates.

\subsection{Statistical analysis}

The different clinical forms of leprosy, the age and sex of participants, the number of seropositive leprosy cases, 
Table 1

Sex and age for leprosy case contacts and no known leprosy contacts, Ceará State, Brazil

\begin{tabular}{|c|c|c|c|c|c|}
\hline & $\begin{array}{l}\text { Case contact from Sobral } \\
(n=380) \\
n(\%)\end{array}$ & $\begin{array}{l}\text { No known contact from Sobral } \\
(n=317) \\
n(\%)\end{array}$ & $P$-value ${ }^{a}$ & $\begin{array}{l}\text { No known contact from Mulungu } \\
(n=87) \\
n(\%)\end{array}$ & $P$-value ${ }^{b}$ \\
\hline \multicolumn{6}{|l|}{ Sex } \\
\hline Male & $139(37)$ & $122(38)$ & $<0.001$ & $16(18)$ & $<0.001$ \\
\hline Female & $241(63)$ & $195(62)$ & & $71(82)$ & \\
\hline \multicolumn{6}{|l|}{ Age (years) } \\
\hline Median (range) & $34(15-95)$ & $39(15-88)$ & 0.04 & $39(18-75)$ & 0.5 \\
\hline$<20$ & $93(24)$ & $45(14)$ & & $5(6)$ & \\
\hline $20-30$ & $82(22)$ & $59(19)$ & & $28(32)$ & \\
\hline $30-40$ & $65(17)$ & $71(22)$ & & $13(15)$ & \\
\hline $40-50$ & $50(13)$ & $58(18)$ & & $23(26)$ & \\
\hline$>50$ & $90(24)$ & $84(26)$ & & $18(21)$ & \\
\hline
\end{tabular}

${ }^{\text {a }}$ Case contact was taken as reference for comparison with no known contact from Sobral.

${ }^{\mathrm{b}}$ No known contact from Sobral was taken as reference for comparison with no known contact from Mulungu.

contacts and no known contacts and their levels of antiPGL-I were compared using $\chi^{2}$ and Wilcoxon tests. The level of significance was $P<0.05$. Stata version 9.0 (Stata Corp., College Station, TX, USA) was used to analyse the data.

\section{Results}

Most leprosy cases, contacts and no known leprosy contacts were females. Contacts were significantly younger than no known contacts in Sobral $(P=0.04$; Table 1$)$.

Among the 144 leprosy cases, 33 were of indeterminate clinical form, 33 were lepromatous, 40 were tuberculoid, 5 were neural and 33 were other forms (Table 2). The median age for MB patients of 52 years was significantly higher than in PB patients $(P=0.001)$. The MB clinical form was significantly more common among male patients $(P<0.001$; Table 3).

The overall seroprevalence of IgM antibody to PGL-I was 36\% among the leprosy cases, but there were variations among those with different clinical forms of leprosy: $61 \%$ in lepromatous cases, $25 \%$ in tuberculoid cases and $0 \%$ in purely neural cases (paucibacillary) (Table 2). The highest IgM anti-PGL-I titre levels were found in lepromatous cases, ranging from 1.7 to 57.1 with a median of 3.8 (Table 2). Among the cases, significantly more males (46\%) than females (24\%) were seropositive for anti-PGL-I $(P=0.006)$. The median age for PGL-I positive cases was 47 years (range 15-88 years), which differed only slightly from the PGL-I negative cases (median 40 years; range 15-86 years). A lower seroprevalence of IgM antibody to PGL-I of $26 \%$ (19/73) was observed in the PB patients compared with MB patients (50\%; 33/66). The median titre level of antiPGL-I for PB patients was 0.5 (range 0-17.6) which was significantly lower than that in MB patients (median 1.7; range $0-57.1 ; P<0.001)$.

The seroprevalence of IgM antibodies to PGL-I was similar among leprosy contacts from Sobral (15.8\%), no known contacts from Sobral (15.1\%) and no known contacts from Mulungu (13.8\%) (Table 4). The median titre levels of antiPGL-I were also similar for leprosy contacts and no known contacts (Table 4). The levels of IgM antibodies against PGL1 for all leprosy cases were significantly higher than the levels of their contacts $(P<0.001)$ and no known leprosy contacts $(P<0.001)$ (data not shown).

Table 2

Seropositivity to anti-phenolic glycolipid-I (PGL-I) and median titre levels of anti-PGL-I in 144 leprosy cases by Ridley-Joplin classification, ${ }^{17}$ sex and age

\begin{tabular}{llll}
\hline & Number of cases & Anti-PGL-I positive $n(\%)$ & Median (range) anti-PGL-I level \\
\hline Classification & & & $3.8(1.7-57.1)$ \\
$\quad$ Lepromatous & 33 & $20(61)$ & $2.1(1.0-15.5)$ \\
Tuberculoid & 40 & $10(25)$ & $1.6(1.0-17.6)$ \\
Indeterminate & 33 & $9(27)$ & $2.4(1.1-4.7)$ \\
Borderline tuberculoid & 19 & $5(21)$ & $1.4(1.7-8.1)$ \\
Borderline borderline & 7 & $4(71)$ & \\
Borderline lepromatous & 7 & 0 & \\
Neural & 5 & $36(46)$ & \\
Sex & & $16(24)$ & \\
Male & 78 & & \\
Female & 66 & $47(15-88)$ & \\
Age (years) & & $3(20)$ & \\
Median (range) & & $11(38)$ & \\
$<20$ & 15 & $8(30)$ & \\
$20-30$ & 29 & $23(30)$ & \\
$30-40$ & 27 & 23 &
\end{tabular}

a Significantly more males than females were seropositive $(P=0.006)$ 
Table 3

Leprosy case distribution by age and sex according to the WHO-operational classification ${ }^{18}$

\begin{tabular}{lll}
\hline & Paucibacillary $(n=73)$ & Multibacillary $(n=66)$ \\
\hline $\begin{array}{l}\text { Age (years) } \\
\text { Median (range) }\end{array}$ & $35(15-85)$ & $52(17-88)$ \\
Sex & & 0.001 \\
Male $(n=78)$ & $27(35 \%)$ & $51(65 \%)$ \\
Female $(n=61)^{\mathrm{a}}$ & $46(75 \%)$ & $15(25 \%)$ \\
\hline
\end{tabular}

a Data were unavailable for five of the 66 female study patients.

b The multibacillary form was more common among males than females.

\section{Discussion}

The results of this study demonstrate that IgM antiPGL-I levels in endemic areas differentiate leprosy cases from non-cases, which was expected since the MB patients presented high BI leading to specific antibody production. However, they do not distinguish household contacts from no known leprosy contacts, or no known contacts from the high and low prevalence areas. The proportion of leprosy patients seropositive to anti-PGL-I among the different clinical forms was similar to that previously reported. 6,7,19,20 Seropositivity was higher among males than females since MB forms are more frequent among men than women. ${ }^{21}$ Studies conducted in endemic areas of northern Malawi and south India found that females were more likely to be PGL-I seropositive. ${ }^{6,22,23}$ These studies also showed that there was an increase in seropositivity among 10-19 year olds. ${ }^{22,24,25}$ In our study, cases were found to be older than their household contacts who had been exposed for a shorter period of time compared with the cases. However, there is no agreement in the published literature on a second increase among individuals above 50 years of age. Our results differ from a study conducted in Venezuela, ${ }^{26}$ which found higher IgM anti-PGL-I levels in household contacts compared to no known leprosy contacts. In the present study, the highest titre levels of anti-PGL-I antibody were found among lepromatous leprosy patients (Table 2 ), and the most elevated level was detected in a patient with a BI of 6.0 presenting as erythema nodosum reaction (titre level of anti-PGL-I = 57.1) at the time of diagnosis. It is worth noting that the results showed the inflammatory reaction course with some bacillary destruction leading to the release of PGL-I and an increase in anti-PGL-I peripheral levels.

As found in the published literature, our study shows that the rate and the levels of anti-PGL-I among the leprosy cases (particularly among lepromatous cases) were higher than among contacts and no known contacts. $6,22,23$ The seropositivity rates seen in our cases were much higher than observed in previously published data. It is not clear how much of this difference is due to variations in the sensitivity of ELISA tests, since the criteria for positivity are based on studies conducted on healthy populations.

The seropositivity rates observed in Sobral among the household contacts were relatively high (median 1.3; range 1.0-6.9) and similar to those seen for individuals not sharing a household with a case (median 1.4; range 1.0-13.0). As Sobral is a highly endemic area, a similar rate between the household contacts and the no known leprosy contacts indicates that a large proportion of the population has been exposed to $M$. leprae bacilli. Several studies have also shown that there is no difference in the seropositivity rate of antiPGL-I among contacts and no known contacts in endemic areas, such as South India ${ }^{6,24}$ and Malawi. ${ }^{22}$

The $14 \%$ anti-PGL-I seropositivity with a median titre level of 1.4 (range 1.0-2.4) in the no known leprosy contacts in Mulungu (Table 4), a community with an incidence rate of almost zero, is intriguing. One possible explanation for this is that although no leprosy cases were diagnosed among the study participants leprosy prevalence rates may be underestimated in the area. Mulungu is located on a mountain surrounded by many towns with prevalence rates higher than $1 / 10000$ inhabitants. During the past decade, commercial trade and tourism have grown intensely, leading to a greater interaction between regional populations and possible increased risk of contact with leprosy patients. Other alternative explanations for the titre levels seen in Mulungu are a potentially high sensitivity of the ELISA test, previous contact with $M$. leprae bacilli elsewhere, and contact with other environmental mycobacteria. As seropositivity to IgM anti-PGL-I might be a risk factor for developing leprosy, ${ }^{5,9}$ the seropositive individuals in Mulungu and Sobral should be monitored for leprosy detection. Douglas and co-authors have already shown that seropositive household contacts and social contacts of leprosy cases have a high risk of developing the disease. $^{27}$

In addition, the possibility of incomplete disease detection must be considered in both towns. If there is a significant underdetection of leprosy, then the real

Table 4

Seropositivity to anti-phenolic glycolipid-I (PGL-I) and median titre levels of anti-PGL-I in contacts and no known contacts of leprosy cases

\begin{tabular}{llll}
\hline & Number of participants & Anti-PGL-I positive $n(\%)$ & Median (range) anti-PGL-I level \\
\hline Case contacts from Sobral & 380 & $60(15.8)$ & $1.3(1.0-6.9)$ \\
No known contacts from Sobral & 317 & $48(15.1)^{\mathrm{a}}$ & $1.4(1.0-13.0)^{\mathrm{a}}$ \\
No known contacts from Mulungu & 87 & $12(13.8)^{\mathrm{a}}$ & $1.4(1.0-2.4)^{\mathrm{a}} \mathrm{b}$
\end{tabular}

a No significant difference was found when compared with case contacts.

${ }^{\mathrm{b}}$ No significant difference was found between no known contacts from Sobral and Mulungu. 
prevalence rate in the state of Ceará is even higher than that reported by the local governmental health agency and this could have implications for control of the disease. On the other hand, over the past 10 years, Sobral has implemented a high quality programme to diagnose, treat and control the disease, resulting in an increase in the detection rates and a decrease in the lapse of follow-up of patient treatment from $20 \%$ to $2.6 \%{ }^{28}$ Therefore, as there are similar seropositivity rates in the two towns, the results suggest that there may be similar cumulative leprosy prevalence rates in Sobral and Mulungu. Thus, the implementation of an early detection programme of index cases and non-leprosy individuals at risk would be helpful in disrupting the mechanisms of the transmission in Mulungu.

An environmental reservoir, which has a role in the transmission and maintenance of the $M$. leprae bacilli in this region may be the reason for the similar seropositivity rates among contacts and no known leprosy contacts from Sobral and no known contacts from Mulungu. Mycobacterium leprae DNA has been detected in several water sources of Mulungu and Sobral, including rivers, ponds and wells (C.C. Frota, unpublished data). In addition, an epidemiological study conducted in the same region reported that frequent contact with contaminated water is a strong risk factor for contracting leprosy disease. ${ }^{29}$ These observations suggest that frequent contact with open water bodies containing M. leprae bacilli for recreational or domestic purposes could stimulate the immune system, increasing anti-PGL-I levels. Recently it has been reported that skin and nasal epithelia of untreated MB leprosy patients could contribute to the shedding of $M$. leprae into the environment. ${ }^{30}$

In conclusion, this study has shown that IgM anti-PGLI antibodies are not useful as immunological markers of household leprosy contacts and no known leprosy contacts in endemic areas. Despite huge differences in the level of reported leprosy cases, the two study regions of Mulungu and Sobral showed similar seropositivity rates and antibody levels. In addition, the prevalence rates of the cases, contacts and no known contacts in both regions are much higher than in other endemic areas. These data indicate that these anti-PGL-I positive populations should be monitored for early leprosy diagnosis.

\section{Authors' contributions}

CCF, MVCF and LRSK performed the analysis and interpretation of these data; NTF and LNCL conducted the immunoassays; CCF, MVCF and LRSK drafted the manuscript; LCR and MLB contributed to data analysis and revised the manuscript; LRSK and MVCF designed the study protocol. All authors read and approved the final manuscript. LRSK is the guarantor of the paper

Acknowledgements: The authors are grateful for the participation of the patients and communities as well as the support of the health authorities of Sobral and Mulungu, Brazil.

Funding: This work was supported by Conselho Nacional de Desenvolvimento Científico e Tecnológico, Brazil (CNPq - 410573/2006-0) and Programa Nacional de Cooperação
Acadêmica (Procad - 204056) of the Coordenação de Pessoal de Nível Superior (CAPES).

\section{Conflicts of interest: None declared.}

Ethical approval: This study was approved by the institutional review board of the Ethical Committee of the Federal University of Ceará, Fortaleza, CE, Brazil. Written consent was obtained from each participant.

\section{References}

1. Burgess PJ, Fine PE, Ponnighaus JM, Draper C. Serological tests in leprosy. The sensitivity, specificity and predictive value of ELISA tests based on phenolic glycolipid antigens, and the implications for their use in epidemiological studies. Epidemiol Infect 1988;101:159-71.

2. Oskam L, Slim E, Buhrer-Sekula S. Serology: recent developments, strengths, limitations and prospects: a state of the art overview. Lepr Rev 2003;74:196-205.

3. Brett SJ, Draper P, Payne SN, Rees RJ. Serological activity of a characteristic phenolic glycolipid from Mycobacterium leprae in sera from patients with leprosy and tuberculosis. Clin Exp Immunol 1983;52:271-9.

4. Cho SN, Yanagihara DL, Hunter SW, Gelber RH, Brennan PJ. Serological specificity of phenolic glycolipid I from Mycobacterium leprae and use in serodiagnosis of leprosy. Infect Immun 1983;41:1077-83.

5. Bakker MI, Hatta M, Kwenang A, Van MP, Faber WR, Klatser PR, et al. Risk factors for developing leprosy-a population-based cohort study in Indonesia. Lepr Rev 2006;77:48-61.

6. Sinha S, Kannan S, Nagaraju B, Sengupta U, Gupte MD. Utility of serodiagnostic tests for leprosy: a study in an endemic population in South India. Lepr Rev 2004;75:266-73.

7. Torres P, Camarena JJ, Gomez JR, Nogueira JM, Gimeno V, Navarro JC, et al. Comparison of PCR mediated amplification of DNA and the classical methods for detection of Mycobacterium leprae in different types of clinical samples in leprosy patients and contacts. Lepr Rev 2003;74:18-30.

8. Cardona-Castro NM, Restrepo-Jaramillo S, Gil de la OM, Brennan PJ. Infection by Mycobacterium leprae of household contacts of lepromatous leprosy patients from a post-elimination leprosy region of Colombia. Mem Inst Oswaldo Cruz 2005;100:703-7.

9. Brasil MTLRF, Oliveira LR, Rímoli NS, Cavallari FS, Gonçalves OS, Lessa ZL, et al. Anti PGL-1 serology and the risk of leprosy in a highly endemic area in the State of São Paulo, Brazil: four-year follow-up. Rev Bras Epidemiol 2003;6:262-71.

10. Ministério da Saúde, Brasil. Avaliação das duplicidades dos casos de hanseníase diagnosticados e notificados no sistema nacional de informação de agravos de notificação, Brasil, 2001-2006. Brasilia: Ministério da Saúde; 2007. http://www.paho. org/portuguese/ $\mathrm{ad} / \mathrm{dpc} / \mathrm{cd} /$ painel-sist-inf.pdf [accessed 1 February 2010].

11. Ministério da Saúde, Brasil. Situação Epidemiológica da Hanseníase no Brasil, 2001-2006. Brasilia: Ministério da Saúde; 2007. http:// portal.saude.gov.br/portal/arquivos/pdf/poster_hansen_brasil.pdf [accessed 1 February 2010].

12. Secretaria de Saúde do Estado do Ceará. Hanseníase: doença em expansão no Ceará. Fortaleza, CE; Governo do Estado do Ceará; 2008. http://www.saude.ce.gov.br/site/index.php?option=com_phocadownload\&view=category\&id=9:boletins\&download=86:2009\& Itemid=247 [accessed 1 February 2010]

13. Montenegro AC, Werneck GL, Kerr-Pontes LR, Barreto ML, Feldmeier $\mathrm{H}$. Spatial analysis of the distribution of leprosy in the State of Ceará, Northeast Brazil. Mem Inst Oswaldo Cruz 2004;99:683-6.

14. van Beers SM, de Wit MY, Klatser PR. The epidemiology of Mycobacterium leprae: recent insight. FEMS Microbiol Lett 1996 1;136:221-30.

15. Kerr-Pontes LR, Montenegro AC, Barreto ML, Werneck GL, Feldmeier $\mathrm{H}$. Inequality and leprosy in Northeast Brazil: an ecological study. Int J Epidemiol 2004;33:262-9.

16. IBGE. Síntese de indicadores sociais: uma analise das condições de vida da população Brasileira. Estudos e Pesquisas; Informação Demográfica e Socioecômica; número 21. Rio de Janeiro: Instituto Brasileiro de Geografia e Estatística; 2007. http://www. ibge.gov.br/home/estatistica/populacao/condicaodevida/indicadoresminimos/sinteseindicsociais2007/indic_sociais2007.pdf [accessed 1 February 2010].

17. Ridley DS, Jopling WH. A classification of leprosy for research purposes. Lepr Rev 1962;33:119-28. 
18. WHO. Chemotherapy of leprosy for control programmes. Report of a WHO Study Group. Geneva: World Health Organization; 1982; Technical Report Series No. 675.

19. Buhrer-Sekula S, Cunha MG, Foss NT, Oskam L, Faber WR, Klatser PR. Dipstick assay to identify leprosy patients who have an increased risk of relapse. Trop Med Int Health 2001;6:317-23.

20. Ponnighaus JM, Fine PEM, Maine N, Bliss L, Kalambo M, Ponnighaus I. The Lepra Evaluation Project (LEP), an epidemiological study of leprosy in northern Malawi. II: Prevalence rates. Lepr Rev 1988;59:97-112.

21. Fine PE. Leprosy: the epidemiology of a slow bacterium. Epidemiol Rev 1982;4:161-88.

22. Fine PE, Ponnighaus JM, Burgess P, Clarkson JA, Draper CC. Seroepidemiological studies of leprosy in northern Malawi based on an enzyme-linked immunosorbent assay using synthetic glycoconjugate antigen. Int J Lepr Other Mycobact Dis 1988;56:243-54.

23. Fine PE. Implications of genetics for the epidemiology and control of leprosy. Philos Trans R Soc Lond B Biol Sci 1988;321(1207):36576.

24. Krishnamurthy P, Rao PS, Reddy BN, Subramanian M, Dhandayudapani S, Bhatia V, et al. Seroepidemiological study of leprosy in a highly endemic population of south India based on an ELISA using synthetic PGL-I. Int J Lepr Other Mycobact Dis 1991;59:426-31.
25. Soebono H, Klatser PR. A seroepidemiological study of leprosy in high- and low-endemic indonesian villages. Int J Lepr Other Mycobact Dis 1991;59:416-25.

26. Ulrich M, Smith PG, Sampson C, Zuniga M, Centeno M, Garcia V, et al. IgM antibodies to native phenolic glycolipid-I in contacts of leprosy patients in Venezuela: epidemiological observations and a prospective study of the risk of leprosy. Int J Lepr Other Mycobact Dis 1991;59:405-15.

27. Douglas JT, Cellona RV, Fajardo Jr TT, Abalos RM, Balagon MV, Klatser PR. Prospective study of serological conversion as a risk factor for development of leprosy among household contacts. Clin Diagn Lab Immunol 2004;11:897-900.

28. Barreto IHC, Andrade LOM, Lira GV, Bezerra FM. A estratégia de Saúde da Família no processo de eliminação da Hanseníase no município de Sobral. In: XVIth International Leprosy Congress: Book of Abstracts; 4-9 August 2002; Salvador, BA, Brazil, p. 261.

29. Kerr-Pontes LR, Barreto ML, Evangelista CM, Rodrigues LC, Heukelbach J, Feldmeier H. Socioeconomic, environmental, and behavioural risk factors for leprosy in North-east Brazil: results of a case-control study. Int J Epidemiol 2006;35:994-1000.

30. Job CK, Jayakumar J, Kearney M, Gillis TP. Transmission of leprosy: a study of skin and nasal secretions of household contacts of leprosy patients using PCR. Am J Trop Med Hyg 2008;78:518- 21. 